\title{
Impact of health facilities on malaria control interventions among children under five years of age and pregnant women in Nigeria
}

\author{
Bolaji Samson Aregbeshola ${ }^{1}$, Samina Mohsin Khan ${ }^{2}$
}

${ }^{1}$ Researcher, Department of Community Health \& Primary Care, College of Medicine, University of Lagos, Idi-Araba, Mushin, Lagos, Nigeria. ${ }^{2} \mathrm{PhD}$ Researcher, Department of Public Health Sciences, Karolinska Institutet, Stockholm, Sweden.

\section{Abstract}

Malaria is still one of the biggest public health problems in Nigeria in spite of numerous control interventions against the disease as well as access to and availability of medicines to address it. The children under five years of age and pregnant women are household members that are most at risk of this disease. The study aims to examine the impact of health facilities on malaria control interventions. Secondary data from Nigeria Demographic and Health Survey 2013 was utilized to investigate the impact of type of health facility visited on malaria control interventions. Variables on malaria control interventions such as malaria prevention in pregnancy, antimalarial drugs and rapid diagnostic testing were analysed. Chi square analysis was used to test for association between variables at 0.05 level of significance. The number of dose of Intermittent Preventive Treatment in Pregnancy (IPTp) taken during pregnancy was associated with private hospital/clinic, government health post and government hospital. The type of antimalarial drug used was associated with the type of health facility visited by children under 5 years. Rapid diagnostic tests (RDTs) for children under 5 years of age was associated with government hospital, government health centre, private hospital/clinic, chemist/patent medicine store and other private medical sector. Our study concludes that the type of health facility visited has an impact on malaria control interventions in Nigeria. There is a need for political actors and policy makers to improve the standard of health care facilities across the country in order to engender the provision of adequate health service delivery to the children under 5 years of age and pregnant women.

Keywords: Malaria, Health Care Facilities, Under Five Children, Pregnant Women, Nigeria.

\section{Introduction}

The 2015 World Malaria Report by the World Health Organization (WHO) showed that Nigeria still has the largest share of malaria burden in Africa ${ }^{1}$ in spite of effort by international organizations over the last fifteen years to reduce the incidence and mortality rate of malaria disease through the design of programs such as Roll Back Malaria (RBM), ${ }^{2}$ Millennium Development Goals (MDGs), ${ }^{3}$ Global Malaria Action Plan (GMAP) ${ }^{4}$ as well as the newly developed Sustainable Development Goals (SDGs) 5 and Global Technical Strategy for Malaria 2016-2030 ${ }^{6}$.

Malaria remain a major public health problem in Nigeria due to weak health system, high rate of poverty, poor investment in the health of the Nigerian population by governments at all levels and inequitable access to quality health care services. The knowledge, attitude and practices of households also contribute to the prevalence of malaria.

Many households especially children under 5 years of age and pregnant women still do not sleep under insecticide treated bed nets (ITNs) due to factors such as family size, level of education, presence of health facility in the community, gender of household head, place of residence, geo-political zone, knowledge that ITNs prevent malaria, marital status and socio-economic status. ${ }^{7-12}$ A lot of households seek malaria treatment in pharmacy stores and other types of places $^{13}$ rather than public or private health facilities. This may be due to better accessibility and shorter waiting time. ${ }^{14}$ Many caregivers and parents do not take their children for diagnostic testing.

\section{Practice Points}

- The type of health facility visited has an impact on malaria control interventions for household members such as children under 5 years of age and pregnant women in Nigeria.

- The number of dose of IPTp taken during pregnancy was associated with private hospital/ clinic, government health post and government hospital.

- The type of health facility visited by children under 5 years of age was associated with the type of antimalarial drug used.

- Rapid diagnostic testing for children under 5 years of age was associated with government hospital, government health centre, private hospital/clinic, chemist/PMS and other private medical sector.

- There is a need for political actors and policy makers to improve the standard of health care facilities across Nigeria in order to engender the provision of adequate health service delivery to children under 5 years and pregnant women.

Pregnant women have limited access to at least two doses of Intermittent Preventive Treatment in Pregnancy (IPTp) with Sulpadoxine Pyrimethamine $(\mathrm{SP})^{15}$ that is supposed to be given monthly based on

Correspondence: Bolaji Samson Aregbeshola, Department of Community Health \& Primary Care, College of Medicine, University of Lagos, Idi-Araba, Mushin, Lagos, Nigeria. Email: bolajiaregbeshola74@gmail.com. 
WHO recommendation and under the supervision of a trained health care provider during the second and third trimester. $^{16,17}$

Malaria is responsible for $60 \%$ of outpatient visits to health facilities, $30 \%$ of childhood deaths, $25 \%$ of deaths in children under one year, and $11 \%$ of maternal deaths. ${ }^{18}$ However, malaria control interventions such as ITNs, IPTp, ACTs and RDTs have led to over 75\% decrease in the incidence of malaria disease between 2000-2015 in African countries such as Algeria, Botswana, Cabo Verde, Eritrea, Namibia, Rwanda, Sao Tome and Principe, South Africa and Swaziland. ${ }^{1}$ Furthermore, malaria control interventions have led to $12 \%$ decrease in number of malaria cases and $48 \%$ decrease in number of malaria deaths in Africa. ${ }^{1}$ Among children under five years of age in Africa, malaria control interventions led to $58 \%$ decrease in number of malaria deaths and $71 \%$ decrease in malaria death rate. ${ }^{1}$

Evidence on the cost-effectiveness of malaria control interventions such as ITNs, IRS, IPTp and RDTs in subSaharan Africa, Asia and South America show different variation in their outcomes with the median cost of administering IPTp to pregnant women substantially less expensive while RDT diagnosis was found to be cost-effective. ${ }^{19-35}$ There is no study conducted to the best of our knowledge on the impact of health facilities on malaria control interventions among the most at risk group using a nationally representative household survey in order to inform policy decisions and aid strategies that will specifically address the burden of malaria among under five children and pregnant women.

The Nigerian Demographic and Health Survey ${ }^{12}$ provide information that can be used to understand the challenges faced by children under five years of age and pregnant women in Nigeria in terms of health facility coverage and health service delivery. The analysis of data on malaria provided by this household survey would assist policy makers and political actors in adopting a holistic approach towards reducing the burden of malaria among these high risk groups to the point that it is no longer a public health challenge.

The aim of the study is to investigate the impact of health care facilities on malaria control interventions among children under five years of age and pregnant women in Nigeria. Specific objectives of the study were to determine the association between type of health facility visited for antenatal care (ANC) by pregnant women and the number of dose of IPTp received for malaria prevention; to determine the relationship between the type of health facility children under five years of age with fever sought care and type of antimalarial drug used; and to determine the association between type of health facility visited and rapid diagnostic test among children under five years of age with fever who sought care.

\section{Materials and methods}

\section{Data source}

Secondary data from the 2013 Nigeria Demographic and Health Survey (NDHS) ${ }^{12}$ was Utilized for the study. NDHS is a nationally representative cross-sectional study conducted by the National Population Commission (NPC) with funding by United States Agency for International Development (USAID), the
United Kingdom Department for International Development (DFID) through Partnership for Transforming Health Systems Phase II (PATHS2), and the United Nations Population Fund (UNFPA) with technical support from ICF International. The NDHS 2013 provides updated estimates of some of the basic demographic and health indicators covered in the earlier surveys such as fertility levels, marriage, fertility preferences, awareness and use of family planning methods, child feeding practices, nutritional status of women and children, adult and childhood mortality, awareness and attitudes regarding HIV/AIDS, in addition, to information on violence against women.

\section{Study areas}

Thirty six states of the federation and the federal capital territory (FCT), Abuja was covered in the survey. A total of 38,700 households were interviewed. The survey used as a sampling frame the list of enumeration areas (EAs) prepared for the 2006 Population Census of the Federal Republic of Nigeria, provided by the National Population Commission. The primary sampling unit (PSU), referred to as a cluster in the NDHS 2013, is defined on the basis of EAs from the 2006 EA census frame. The 2013 NDHS sample was selected using a stratified three-stage cluster design consisting of 904 clusters, 372 in urban areas and 532 in rural areas.

\section{Data collection}

Data was collected through interviews conducted by NPC enumerators with household members on a quarterly basis from February 2013 to June 2013. In obtaining the micro data, a request was made on the DHS program website on March 25, 2016 and approval was granted to download the data on March 28, 2016.

\section{Data analysis}

Data were analysed using SPSS version 22 software. A significance level of $p<0.05$ was used.

\section{Results}

Descriptive statistics

Table 1 present the socio-demographic characteristics of respondents. The majority of respondents were aged between 25-29 years (27.9\%). Among the study population, $46.3 \%$ had no education, $31.8 \%$ had primary education, $16.8 \%$ had secondary education and $5.1 \%$ had higher education. Majority of household heads were males $(89.4 \%)$ while only $10.6 \%$ were females. A total $(76.0 \%)$ of households had more than five members while only $24.0 \%$ had households with less than five members. Majority of the population $(67.1 \%)$ lived in rural area while only $32.9 \%$ lived in urban area. Most of the respondents $(98.3 \%)$ lacked health insurance while only $1.7 \%$ were under health insurance coverage. Respondents consisted of households and individuals from the six geo-political zones: North Central (14.7\%), North East (20.7\%), North West (31.5\%), South East (8.9\%), South South (11.9\%) and South West (12.3\%).

Association between health facility visited and doses of IPTp

The number of dose of IPTp with SP taken by pregnant women during pregnancy was significantly associated with private hospital/clinic $(p=0.000)$, government health post $(p=0.000)$ and government hospitals $(p=0.020)$. Details are given in Table 2 . 
Table 1: Socio-demographic characteristics of the respondents

\begin{tabular}{|c|c|}
\hline $\begin{array}{l}\text { Household and Individu- } \\
\text { al Characteristics }\end{array}$ & $\begin{array}{l}\text { Respondents }(\%) \\
(n=31482)\end{array}$ \\
\hline \multicolumn{2}{|l|}{ Age in 5 years } \\
\hline $15-19$ & $1543(4.9 \%)$ \\
\hline $20-24$ & $6076(19.3 \%)$ \\
\hline $25-29$ & $8783(27.9 \%)$ \\
\hline $30-34$ & $6926(22.0 \%)$ \\
\hline $35-39$ & $4911(15.6 \%)$ \\
\hline $40-44$ & $2330(7.4 \%)$ \\
\hline $45-49$ & $912(2.9 \%)$ \\
\hline \multicolumn{2}{|l|}{ Highest Education } \\
\hline None & $14576(46.3 \%)$ \\
\hline Primary & $10011(31.8 \%)$ \\
\hline Secondary & $5289(16.8 \%)$ \\
\hline Higher & $1606(5.1 \%)$ \\
\hline \multicolumn{2}{|l|}{ Gender of Household Head } \\
\hline Male & $28145(89.4 \%)$ \\
\hline Female & $3337(10.6 \%)$ \\
\hline \multicolumn{2}{|l|}{ Household Size } \\
\hline Less than 5 members & $7556(24.0 \%)$ \\
\hline More than 5 members & $23926(76.0 \%)$ \\
\hline \multicolumn{2}{|l|}{ Location } \\
\hline Urban & $10358(32.9 \%)$ \\
\hline Rural & $21124(67.1 \%)$ \\
\hline \multicolumn{2}{|l|}{ Geo-political Zone } \\
\hline North Central & $4628(14.7 \%)$ \\
\hline North East & $6517(20.7 \%)$ \\
\hline North West & $9917(31.5 \%)$ \\
\hline South East & $2802(8.9 \%)$ \\
\hline South South & $3746(11.9 \%)$ \\
\hline South West & $3872(12.3 \%)$ \\
\hline \multicolumn{2}{|l|}{ Socio-economic Status } \\
\hline Poorest & $7083(22.5 \%)$ \\
\hline Poorer & $7398(23.5 \%)$ \\
\hline Middle & $6265(19.9 \%)$ \\
\hline Richer & $5793(18.4 \%)$ \\
\hline Richest & $4943(15.7 \%)$ \\
\hline \multicolumn{2}{|l|}{ Health Insurance Coverage } \\
\hline Lack health insurance & $30947(98.3 \%)$ \\
\hline Under health insurance & $535(1.7 \%)$ \\
\hline \multicolumn{2}{|l|}{ Marital Status } \\
\hline Never Married & $598(1.9 \%)$ \\
\hline Married & $29121(92.5 \%)$ \\
\hline Living with partner & $881(2.8 \%)$ \\
\hline Widowed & $379(1.2 \%)$ \\
\hline Divorced & $283(0.9 \%)$ \\
\hline Separated & $220(0.7 \%)$ \\
\hline
\end{tabular}

Association between health facility visited by children and antimalarial drug used

Table 3 present result of the association between type of health facility visited by children under 5 years of age and type of antimalarial drug used. There was a statistically significant association between type of health facility visited and type of anti-malaria drug used.

Association between health facility visited and rapid diagnostic test for children

Rapid diagnostic tests (RDTs) for children under 5 years of age was statistically associated with government hospital $(p=0.000)$, government health centre $(p=0.000)$, private hospital/clinic $(p=0.000)$, chemist/PMS $(p=0.000)$ and other private medical sector $(p=0.007)$. Details are given in Table 4 .

\section{Discussion}

According to the Central Intelligence Agency World Fact Sheet 2015 estimates, over 60 per cent of the Nigerian population are under the age of 24 years, 25.92 per cent are between the ages of 25 to 54 years while only 3.11 per cent are 65 years and above. About 30 million people are under five years of age while 42 million females are within the reproductive age. This explains the reason infectious diseases such as malaria is a big problem in Nigeria, though, noncommunicable diseases such as cancer, hypertension, stroke, diabetes and cardiovascular diseases are also fast becoming epidemic. Therefore, Nigeria is battling a dual epidemic.

Our study show that the type of health facility visited by children under 5 years and pregnant women have an impact on the survival against malaria cases and deaths, hence, governments and decision makers need to work towards the provision of adequate and wellequipped health care facilities for the benefit of the Nigerian population. The children under 5 years of age and pregnant women are the most at risk group and susceptible to malaria illness. ${ }^{36,37}$ These two groups are often vulnerable and disadvantaged besides they are worst hit by malaria which is a one of the diseases of poverty. ${ }^{38}$ Approximately one in eight children die before their fifth birthday ${ }^{12}$ while malaria contributes to an estimated $11 \%$ of maternal mortality in Nigeria. ${ }^{39}$

Nigeria account for over $20 \%$ of both malaria cases and malaria deaths among fifteen countries in sub Saharan Africa that has the highest burden of malaria disease. ${ }^{1}$ The National Malaria Strategic Plan 20142020 stated that malaria is responsible for 60 per cent of outpatient visits to health facilities. ${ }^{18}$ The children under 5 years of age and pregnant women constitute a larger per cent of patients that visit these health facilities and experience barriers to access health care services due to ill-equipped health facilities and infrastructure. ${ }^{40,41}$ Result from our study show that the number of doses of IPTp during pregnancy was

Table 2: Association between types of health facility visited for ANC and number of IPTp taken

\begin{tabular}{|c|c|c|c|c|c|c|}
\hline \multirow[t]{2}{*}{$\begin{array}{l}\text { Type of facility visited } \\
\text { for ANC }\end{array}$} & \multicolumn{3}{|c|}{$\begin{array}{l}\text { Number of dose of SP was taken by the } \\
(\%)\end{array}$} & respondents & \multirow[t]{2}{*}{$\begin{array}{l}\text { Chi } \\
\text { square }\end{array}$} & \multirow[t]{2}{*}{$p$-value } \\
\hline & 1 & 2 & 3 & $>$ than 3 & & \\
\hline Private hospital/clinic & $5126(41.1 \%)$ & $3867(31.0 \%)$ & $2195(17.6 \%)$ & $1285(10.3 \%)$ & 51.43 & $p=0.000$ \\
\hline Government health post & $3068(24.6 \%)$ & $3131(25.1 \%)$ & $5850(46.9 \%)$ & $424(3.4 \%)$ & 104.57 & $p=0.000$ \\
\hline Government health centre & $4727(37.9 \%)$ & $4665(37.4 \%)$ & 2395( & $5 \%)$ & 16.79 & $p=0.469$ \\
\hline Government hospital & $4415(35.4 \%)$ & $5090(40.8 \%)$ & $2145(17.2 \%)$ & $823(6.6 \%)$ & 30.93 & $p=0.020$ \\
\hline At home & $4378(35.1 \%)$ & $4378(35.1 \%)$ & $2694(21.6 \%)$ & $1023(8.2 \%)$ & 1.975 & $p=1.000$ \\
\hline
\end{tabular}

South East Asia Journal of Public Health 2017;7(1):35-41 
Table 3: Association between type of facility visited by febrile children and type of antimalarial drugs used

\begin{tabular}{|c|c|c|c|c|c|c|c|}
\hline \multirow{2}{*}{$\begin{array}{l}\text { Healthcare facilities } \\
\text { visited }\end{array}$} & \multicolumn{7}{|c|}{ Number of febrile children who took antimalarial drugs (\%) } \\
\hline & 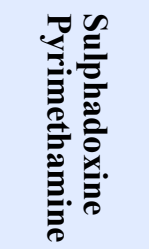 & 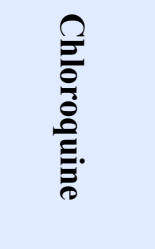 & 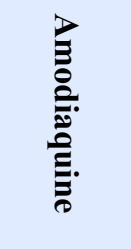 & 䙲. & 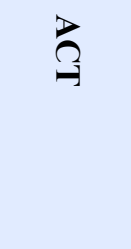 & $\stackrel{0}{\stackrel{0}{0}}$ & 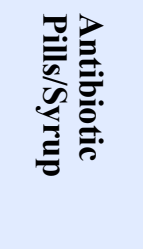 \\
\hline Government hospital & $\begin{array}{c}679 \\
(18.7 \%)^{*}\end{array}$ & $\begin{array}{c}585 \\
(16.1 \%)^{*}\end{array}$ & $\begin{array}{c}80 \\
(2.2 \%) \\
\end{array}$ & $\begin{array}{c}15 \\
(0.4 \%)\end{array}$ & $\begin{array}{c}356 \\
(9.8 \%)^{*}\end{array}$ & $\begin{array}{c}341 \\
(9.4 \%)^{*}\end{array}$ & $\begin{array}{c}1271 \\
(35.0 \%)^{*}\end{array}$ \\
\hline Govt. health centre & $\begin{array}{c}400 \\
(11.0 \%)^{*}\end{array}$ & $\begin{array}{c}668 \\
(18.4 \%)^{*}\end{array}$ & $\begin{array}{c}94 \\
(2.6 \%)^{*}\end{array}$ & $\begin{array}{c}62 \\
(1.7 \%)^{*}\end{array}$ & $\begin{array}{c}316 \\
(8.7 \%)^{*}\end{array}$ & $\begin{array}{c}283 \\
(7.8 \%)^{*}\end{array}$ & $\begin{array}{c}1180 \\
(32.5 \%) *\end{array}$ \\
\hline Mobile clinic & $\begin{array}{c}519 \\
(14.3 \%)\end{array}$ & 0 & 0 & 0 & 0 & 0 & 0 \\
\hline Govt. health post & $\begin{array}{c}458 \\
(12.6 \%)\end{array}$ & $\begin{array}{c}327 \\
(9.0 \%)\end{array}$ & $\begin{array}{c}163 \\
(4.5 \%)^{*}\end{array}$ & 0 & $\begin{array}{c}360 \\
(9.9 \%)^{*}\end{array}$ & $\begin{array}{c}262 \\
(7.2 \%)\end{array}$ & $\begin{array}{c}1406 \\
(38.7 \%)\end{array}$ \\
\hline Other public sector & 0 & 0 & 0 & 0 & 0 & 0 & $\begin{array}{c}2423 \\
(66.7 \%)\end{array}$ \\
\hline Private hospital/clinic & $\begin{array}{c}588 \\
(16.2 \%)^{*}\end{array}$ & $\begin{array}{c}327 \\
(9.0 \%)\end{array}$ & $\begin{array}{c}65 \\
(1.8 \%)\end{array}$ & $\begin{array}{c}18 \\
(0.5 \%)\end{array}$ & $\begin{array}{c}280 \\
(7.7 \%)\end{array}$ & $\begin{array}{c}490 \\
(13.5 \%)^{*}\end{array}$ & $\begin{array}{c}1406 \\
(38.7 \%)^{*}\end{array}$ \\
\hline Private pharmacy & $\begin{array}{c}559 \\
(15.4 \%)^{*}\end{array}$ & $\begin{array}{c}149 \\
(4.1 \%)\end{array}$ & 0 & $\begin{array}{c}29 \\
(0.8 \%) \\
\end{array}$ & $\begin{array}{c}294 \\
(8.1 \%)\end{array}$ & $\begin{array}{c}592 \\
(16.3 \%)^{*}\end{array}$ & $\begin{array}{c}1064 \\
(29.3 \%)\end{array}$ \\
\hline Private doctor & 0 & $\begin{array}{c}970 \\
(26.7 \%) *\end{array}$ & 0 & $\begin{array}{c}243 \\
(6.7 \%)^{*}\end{array}$ & $\begin{array}{c}243 \\
(6.7 \%)\end{array}$ & $\begin{array}{c}483 \\
(13.3 \%)\end{array}$ & $\begin{array}{c}726 \\
(20.0 \%)\end{array}$ \\
\hline Chemist/PMS & $\begin{array}{c}251 \\
(6.9 \%)^{*}\end{array}$ & $\begin{array}{c}341 \\
(9.4 \%)\end{array}$ & $\begin{array}{c}47 \\
(1.3 \%) \\
\end{array}$ & $\begin{array}{c}22 \\
(0.6 \%)\end{array}$ & $\begin{array}{c}167 \\
(4.6 \%)\end{array}$ & $\begin{array}{c}262 \\
(7.2 \%)\end{array}$ & $\begin{array}{c}1162 \\
(32.0 \%) *\end{array}$ \\
\hline Other private sector & 0 & 0 & 0 & 0 & 0 & $\begin{array}{c}330 \\
(9.1 \%)\end{array}$ & - \\
\hline Traditional practitioner & $\begin{array}{c}142 \\
(3.9 \%)\end{array}$ & $\begin{array}{c}58 \\
(1.6 \%)^{*}\end{array}$ & 0 & 0 & $\begin{array}{c}29 \\
(0.8 \%)^{*}\end{array}$ & 0 & - \\
\hline
\end{tabular}

Table 4: Association between type of facility visited and rapid diagnostic test for children

\begin{tabular}{|l|c|c|c|c|}
\hline \multirow{2}{*}{$\begin{array}{l}\text { Health Facilities where advice was } \\
\text { sought }\end{array}$} & \multicolumn{2}{|l|}{ Blood taken by the respondents } & \multirow{2}{*}{ Chi square } & \multirow{2}{*}{-value } \\
\cline { 2 - 3 } & Yes & No & & \\
\hline Government hospital & $1155(31.8 \%)$ & $403(11.1 \%)$ & 127.80 & $p=0.000$ \\
\hline Government health centre & $726(20.0 \%)$ & $360(9.9 \%)$ & 36.20 & $p=0.000$ \\
\hline Mobile clinic & 0 & $7(0.2 \%)$ & 0.78 & $p=0.679$ \\
\hline Government health post & $130(3.6 \%)$ & $98(2.7 \%)$ & 1.25 & $p=0.535$ \\
\hline Other public sector & 0 & $4(0.1 \%)$ & 0.39 & $p=0.824$ \\
\hline Private hospital/clinic & $476(13.1 \%)$ & $138(3.8 \%)$ & 64.88 & $p=0.000$ \\
\hline Private pharmacy & $65(1.8 \%)$ & $98(2.7 \%)$ & 1.12 & $p=0.570$ \\
\hline Private doctor & $11(0.3 \%)$ & $15(0.4 \%)$ & 0.19 & $p=0.911$ \\
\hline Chemist/PMS & $643(17.7 \%)$ & $1434(39.5 \%)$ & 70.59 & $p=0.000$ \\
\hline Other private sector & $36(1.0 \%)$ & $7(0.2 \%)$ & 9.89 & $p=0.007$ \\
\hline Traditional practitioner & $54(1.5 \%)$ & $127(3.5 \%)$ & 4.24 & $p=0.120$ \\
\hline
\end{tabular}

associated with private hospitals, government health post and government hospital. WHO recommend that at least two doses of IPTp with SP be given to all pregnant women during pregnancy. ${ }^{16,17}$ In this study, between $25 \%$ to $41 \%$ of pregnant women received two doses of IPTp with SP. Similar studies conducted in South East ${ }^{42}$, South West $^{43-45}$, North East ${ }^{46}$ and at the national level in Nigeria $^{47}$ showed that about $37 \%$ of pregnant women received two doses of IPTp less than the target of RBM program indicating low adherence and uptake of IPTp for patients who sought care at health facilities. A study conducted in Uganda also show that only about a quarter of pregnant women receive two doses of IPTp with SP. ${ }^{48}$

However, these findings are in contrast with studies conducted in Central Mozambique ${ }^{49}$, Dar es Salaam ${ }^{50}$ and Uganda $^{51}$ where the uptake level for IPTp ranged between $52 \%$ to $92 \%$. Poor uptake or adherence to IPTp could be responsible for the prevalence rate of malaria in pregnancy across Nigeria ranging between $19.7 \%$ to $72 \% .{ }^{52-55}$ Furthermore, malaria is responsible for $30 \%$ hospitalization among children under five years of age in Nigeria. ${ }^{56}$ WHO also recommend Artemisinin-Based Combination Therapies (ACTs) as the drug of choice due to its safety and tolerability in young children. Nigeria adopted ACTs as the first line treatment for uncomplicated malaria in 2005. Our study found that the type of antimalarial drug used was associated with seeking advice/treatment at government hospital and government health centre. In this study, between $0.8 \%$ to $9.9 \%$ of febrile under 5 children who visited health facilities used ACTs. Studies conducted on the use of ACTs among under five children in Osun State ${ }^{57}$ and Ekiti State ${ }^{58}$ in Nigeria found that less than $10 \%$ of children 
under five years of age utilised ACTs. Prompt diagnostic testing for children under 5 years of age before treatment and without delaying treatment is recommended by WHO. Our study found that the diagnostic testing for children under 5 years of age was associated with seeking advice/treatment at government hospital, government health centre, private hospital/ clinic, chemist/PMS and other private medical sector. Furthermore, mainly government health facilities are doing well but even then only $20 \%$ to $32 \%$ of children under 5 years of age is being tested for blood. However, only $0.3 \%$ to $18 \%$ of children under 5 years of age are being tested for blood in private health facilities. This is supported by a study in Benin, the Democratic Republic of Congo (DRC), Madagascar, Nigeria, Uganda and Zambia where only $2 \%$ to $16 \%$ of febrile children under five years of age received a malaria blood test in private health facilities prior to treatment. ${ }^{59}$ Most children under 5 years of age and pregnant women in Nigeria often have a poor economy that constraint them from seeking the best medical care. This group constitute a larger percentage of the Nigerian population and are prone to infectious diseases. ${ }^{19,20}$ Though there are numerous programs and interventions at both the state and national levels but the malaria situation in Nigeria does not seem to be changing for the better. There is a need to evaluate the effect of the different malaria control interventions to determine factors responsible for the slow decline recorded over the decade in fighting malaria disease. This will assist decision makers and governments in rethinking their strategies and improving malaria control intervention towards elimination of the disease.

\section{Limitations}

Our study has some limitations but this does not invalidate our work. The 2013 NDHS dataset used in the study is affected by the structure of the questionnaire, mode of data collection, recall bias as well as issues of validity, reliability and comparability.

\section{Conclusion}

Our study concludes that health care facilities have an impact on malaria control interventions for children under five years of age and pregnant women in Nigeria. Findings from the study showed that there is low uptake of malaria control interventions such as IPTp, ACTs and RDTs among pregnant women and children under 5 years of age. This implies that health care facilities are ill-equipped to address the high burden of malaria in Nigeria.

Governments should pay attention to the challenges of availability of and accessibility to well-equipped health care facilities for these high risk groups in order to improve their health status and reduce the high mortality rate that is consistently recorded among these groups. Addressing the burden of malaria among children under five years and pregnant women through the availability of and accessibility to well-equipped health facilities will tremendously improve health indicators such as under five mortality, infant mortality and maternal mortality. Policy makers and political actors across Nigeria should show strong commitment to the plight of children and pregnant women and improve access to health delivery services through the provision of wellequipped physical infrastructure within the specified standard. In addition, governments should ensure the availability of drugs in health care facilities as well as the monitoring and training of health care workers on the national treatment guidelines.

\section{Competing interest}

The authors declare that they have no competing interests.

\section{References}

1. World Health Organization. World Malaria Report 2015. Geneva: WHO, 2015.

2. World Health Organization. Roll Back Malaria: Report by the Director-General. Fifty Second World Health Assembly. http://apps.who.int/gb/ archive/pdf files/WHA52/ew6.pdf (accessed May 2017)

3. United Nations. The Millennium Development Goals. http://www.un.org/en/mdg/summit2010/ pdf/List $\% 20$ of $\% 20$ MDGs $\% 20$ English.pdf (accessed May 2017)

4. Roll Back Malaria Partnership. Global Malaria Action Plan: For a malaria-free world. Geneva: World Health Organization, 2008.

5. United Nations Development Programme. Sustainable Development Goals. http:// www.undp.org/content/dam/undp/library/ corporate/brochure/SDGs Booklet Web En.pdf (accessed May 2017)

6. World Health Organization. Global technical strategy for malaria 2016-2030. Geneva: WHO, 2015.

7. Oresanya OB, Hoshen M, Sofola OT. Utilization of insecticide-treated nets by under-five children in Nigeria: Assessing progress towards the Abuja targets. Malaria J 2008;7:145:1-15

8. Auta A. Demographic factors associated with insecticide-treated nets use among Nigerian women and children. $N$ Am J Med Sci 2012;4 (1):40-4.

9. Ezire O, Adebayo SB, Idogho O, Bamgboye EA, Nwokolo E. Determinants of use of insecticidetreated nets among pregnant women in Nigeria. Int J Womens Health 2015;7:655-61.

10. Ezeama M, Ezeamah F, Akor QG. Factors militating against the use of insecticide treated nets among pregnant women in Nigeria. IJRMS 2014;4(9):8-14.

11. Ankomah A, Adebayo SB, Arogundade ED, Anyanti J, Nwokolo E, Ladipo O, et al. Determinants of insecticide-treated net ownership and utilization among pregnant women in Nigeria. BMC Public Health 2012;12:105:2-10.

12. National Population Commission (NPC) [Nigeria] and ICF International. Nigeria Demographic and Health Survey 2013. Abuja, Nigeria, and Rockville, Maryland, USA: NPC and ICF International, 2014.

13. Hanson $\mathrm{K}$, Goodman $\mathrm{C}$, Lines $\mathrm{J}$, Meek $\mathrm{S}$, 
Bradley D, Mills A. The economics of malaria control interventions. Geneva: Global Forum for Health Research, 2004.

14. Brugha R, Zwi A. Improving the quality of private sector delivery of public health services: challenges and strategies. Health Policy Plan 1998;13:107-20.

15. Onoka CA, Onwujekwe OE, Hanson K, Uzochukwu BS. Sub-optimal delivery of intermittent preventive treatment for malaria in pregnancy in Nigeria: Influence of provider factors. Malaria J 2012;11:317.

16. World Health Organization. WHO evidence review group meeting report: IPTp-SP. http:// www.who.int/malaria/mpac/sep2012/ iptp sp erg meeting report july2012.pdf (accessed May 2017)

17. World Health Organization. Intermittent preventive treatment in pregnancy (IPTp): key documents and guidelines. http://www.who.int/ malaria/areas/preventive therapies/pregnancy/ en/index.html (accessed May 2017)

18. Federal Republic of Nigeria. National Malaria Strategic Plan 2014-2020. http:// www.nationalplanningcycles.org/sites/default/ files/planning cycle repository/nigeria/ nigeria national malaria strategic plan.pdf (accessed May 2017)

19. Kolaczinski J, Hanson K. Costing the distribution of insecticide-treated nets: a review of cost and cost-effectiveness studies to provide guidance on standardization of costing methodology. Malaria J 2006;5:37.

20. Goodman CA, Mills AJ. The evidence base on the cost-effectiveness of malaria control measures in Africa. Health Policy Plan 1999; 14:301-12.

21. Walker D, Fox-Rushby JA. Economic evaluation of communicable disease interventions in developing countries: A critical review of the published literature. Health Econ 2000;9:681-98.

22. Goodman CA, Coleman PG, Mills AJ. Costeffectiveness of malaria control in sub-Saharan Africa. Lancet 1999;354:378-85.

23. Morel CM, Lauer JA, Evans DB. Achieving the millennium development goals for health - Cost effectiveness analysis of strategies to combat malaria in developing countries. $B M J$ 2005;331:1299-1302B.

24. Adam T, Evans DB, Murray CJL. Econometric estimation of country-specific hospital costs. Cost Eff Resour Alloc 2003;1(3).

25. Akhavan D, Musgrove P, Abrantes A, Gusmao RD. Cost-effective malaria control in Brazil Cost-effectiveness of a malaria control program in the Amazon Basin of Brazil, 1988-1996. Soc Sci Med 1999;49:1385-99.

26. Conteh L, Sicuri E, Manzi F, Hutton G, Obonyo $\mathrm{B}$, Tediosi $\mathrm{F}$ et al. The cost-effectiveness of intermittent preventive treatment for malaria in infants in sub-Saharan Africa. PLoS ONE 2010;5 (6):e10313.

27. Chanda P, Castillo-Riquelme M, Masiye F. Costeffectiveness analysis of the available strategies for diagnosing malaria in outpatient clinic in Zambia. Cost Eff Resour Alloc 2009;7(5).

28. Yukich J, D'Acremont V, Kahama J, Swai N, Lengeler C. Cost savings with Rapid Diagnostic Tests for malaria in low-transmission areas: Evidence from Dar es Salaam, Tanzania. Am J Trop Med Hyg 2010; 83(1):61-8.

29. Lemma H, San Sebastian M, Lofgren C, Barnabas G. Cost-effectiveness of three malaria treatment strategies in rural Tigray, Ethiopia where both Plasmodium falciparum and Plasmodium vivax co-dominate. Cost Eff Resour Alloc 2011;9:2-10.

30. Rolland E, Checchi F, Pinoges L, Balkan S, Guthmann JP, Guerin PJ. Operational response to malaria epidemics: are rapid diagnostic tests cost-effective? Trop Med Int Health 2006;11:398 -408 .

31. Bhatia MR, Fox-Rushby J, Mills A. Costeffectiveness of malaria control interventions when malaria mortaility is low: insecticidetreated nets versus in-house residual spraying in India. Soc Sci Med 2004;59:525-39.

32. Kamolratanakul P, Butraporn P, Prasittisuk M, Prasittisuk C, Indaratna K. Cost-effectiveness and sustainability of lambdacyhalothrin-treated mosquito nets in comparison to DDT spraying for malaria control in western Thailand. $A m J$ Trop Med Hyg 2001;65:279-84.

33. Goodman CA, Mnzava AEP, Dlamini SS, Sharp BL, Mthembu DJ, Gumede JK. Comparison of the cost and cost-effectiveness of insecticidetreated bednets and residual house-spraying in KwaZulu-Natal, South Africa. Trop Med Int Health 2001;6:280-95.

34. Guyatt HL, Kinnear J, Burini M, Snow RW. A comparative cost analysis of insecticide-treated nets and indoor residual spraying in highland Kenya. Health Policy Plan 2002;17:144-53.

35. White MT, Conteh L, Cibulskis R, Ghani AC. Cost and cost-effectiveness of malaria control interventions - a systematic review. Malaria $J$ 2011;10:337.

36. World Health Organization. Malaria: High risk group. http://www.who.int/malaria/areas/ high_risk_groups/en/ (accessed May 2017)

37. World Health Organization. Malaria Fact Sheet: World Malaria Report 2015. http://www.who.int/ malaria/media/world-malaria-report-2015/en/ (accessed May 2017)

38. United Nations Children's Fund. Malaria: A major cause of child death and poverty in Africa. New York: UNICEF, 2014.

39. Federal Ministry of Health. Malaria situation analysis document. Nigeria: FMOH, 2000.

40. Olsen OE, Ndeki S, Norheim OF. Complicated deliveries, critical care and quality in emergency 
obstetric care in Northern Tanzania. Int $J$ Gynaecol Obstet 2004;87:98-108.

41. Rutherford ME, Dockerty JD, Jasseh M, Howie $\mathrm{S}$, Herbison P, Jefferies DJ et al. Access to health care and mortality of children under 5 years of age in the Gambia: a case-control study. Bull World Health Organ 2009;87:216-24

42. Nduka FO, Nwosu E, Oguariri RM. Evaluation of the effectiveness and compliance of IPTp in the control of malaria in pregnant women in South-Eastern Nigeria. Ann Trop Med Parasitol 2011;105:599-605.

43. Olorunda DC, Ajayi IO, Falade CO. Do frequent ANC visits ensure access and adherence to IPTp in an urban hospital in South Western Nigeria? Afr J Biomed Res 2013;16(3):153-61.

44. Akinleye SO, Falade CO, Ajayi IO. Knowledge and utilization of intermittent preventive treatment for malaria among pregnant women attending antenatal clinics in PHC centers in rural South West Nigeria: a cross-sectional study. BMC Pregnancy Childbirth 2009;9:28.

45. Akpasa AO, Adebayo A, Onyilo J, Ahmed B, Ladipo TO, Oke Y et al. Uptake of intermittent preventive therapy among pregnant women attending antenatal clinic in public and registered private health facilities in Oyo State, Nigeria. Int $J$ Infect Dis 2016;45(1):272-3.

46. Jibo AM. Adherence to IPTp in urban Kano, northern Nigeria. Pathog Glob Health 2012;106 (6): 323-329.

47. Brieger W. Control of malaria in pregnancy: an elusive target. Afr Health 2012;Jan:12-8. (accessed May 2017)

48. Malaria Consortium. The challenges: children and malaria. http://www.malariaconsortium.org/ pages/malaria challenges.html (accessed May 2016)

49. Brentlinger PE, Dgedge M, Correia MA, et al. Intermittent preventive treatment of malaria during pregnancy in Central Mozambique. Bull World Health Organ 2007;85(11):873-9.

50. Nyonyi JK. Factors affecting the implementation of intermittent preventive treatment of malaria in pregnancy in Dar es Salaam health facilities. MPH dissertation. Muhimbili University of Health and Allied Sciences, 2012.
51. Ndyomugyenyi R, Katamanywa J. IPTp: do f requent ANC visits ensure access and compliance to IPTp in Ugandan rural communities? Trans R Soc Trop Med Hyg 2010;104:536-40.

52. Okwa OO. The status of malaria among pregnant women: a study in Lagos, Nigeria. Afr J Reprod Health 2003;7:77-83.

53. Adefuye OA, Adeyeba OA, Hassan WO, Oyeniran OA. Prevalence of malaria parasite infection among pregnant women in Osogbo, South West, Nigeria. American-Eurasian J Sci Res 2007;2:43-45.

54. Kagu MB, Kawuwa MB, Gadzama GB Anaemia in pregnancy: a cross-sectional study of pregnant women in a Sahelian tertiary hospital in North Eastern Nigeria. J Obstet Gynecol 2007;27:676-9.

55. Uneke CJ. Assessment of malaria in pregnancy using rapid diagnostic test and its association with HIV infection and hematologic parameters in South Eastern Nigeria. Haematologia 2008;93:143-4.

56. United States Embassy in Nigeria. Nigeria malaria fact sheet. http://photos.state.gov/ libraries/nigeria/231771/Public/DecemberMalariaFactSheet2.pdf (accessed May 2017)

57. Adeyemo MO, Oluwatosin A, Osuala EO, Oladapo MM, Lawal-Adeyemo AA. Awareness and utilization of artemisinin-based combination therapies among mothers of under-five children in a local government area in Nigeria. App Sci Report 2017;17(2):35-40.

58. Oluwasogo AO, Henry OS, Abdulrasheed AA, Olawumi TA, Olabisi EY. Assessment of mothers knowledge and attitude towards management of under five years children in Okemesi Ekiti, Ekiti West Local Government, Ekiti State Estrjkl. Malaria Contr Elimination 2016;5:142.

59. Littrell M, Gatakaa H, Evance I, Poyer S, Njogu $\mathrm{J}$, Solomon $\mathrm{T}$ et al. Monitoring fever treatment behaviour and equitable access to effective medicines in the context of initiatives to improve ACT access: baseline results and implications for programming in six African countries. Malaria $J$ 2011;10:327. 